\title{
Basic Physical, Mechanical, Thermal and Hygric Properties of Concrete with Coarse Aggregates Fabricated from Recycled Concrete Pavements
}

\author{
Lukáš Fiala ${ }^{1, *}$, Magdaléna Doleželová ${ }^{1}$,Václav Kočí1, Wei-Ting Lin ${ }^{2}$, and Izabela Hager ${ }^{3}$ \\ ${ }^{1}$ Czech Technical University in Prague, Faculty of Civil Engineering, Thákurova 7, 16629 Prague, \\ Czech Republic \\ ${ }^{2}$ National Ilan University, College of Engineering, Department of Civil Engineering, No.1, Sec. 1, \\ Shennong Rd., I-Lan 260, Taiwan \\ ${ }^{3}$ Cracow University of Technology, Faculty of Civil Engineering, Institute of Building Materials and \\ Engineering Structures, Warszawska 24, 31155 Krakow, Poland
}

\begin{abstract}
Concrete production unfavourably affects the environment due to high energy demands of cement production and consumption of limited natural resources. Therefore, waste utilization in fabrication of cementitious material is beneficial and legitimate. Significant reduction of environmental impact can be secured by utilization of various types of wastes or byproducts used for a partial substitution of cement binder or aggregates. However, the use of waste materials usually leads to deterioration of material properties of the designed composites. Therefore, it is very important to thoroughly investigate important materials properties to verify performance and practical usability of the newly designed materials. In this paper, three types of concrete mixes were designed. The reference concrete involved fine and coarse natural riverbed aggregates and two other mixes were designed using both, natural and recycled aggregates represented by crushed concrete paving cobbles. Concretes were tested in terms of basic physical properties (bulk density), mechanical properties (compressive strength), thermal properties (thermal conductivity, specific heat capacity, thermal diffusivity), and hygric properties (water vapour diffusion resistance factor, water vapour sorption at $97 \% \mathrm{RH}$, water absorption coefficient, moisture diffusivity) and experimentally determined data were compared and discussed. It was observed that materials properties of concretes with recycled aggregates are comparable with those of the reference concrete which is a promising fact from the environmental point of view.
\end{abstract}

\section{Introduction}

The utilization of recycled materials in the construction industry is systematically gaining on importance. It is mainly due to an increasing amount of waste resulting from an

* Corresponding author: fialal@fsv.cvut.cz 
increasing industrial production process of various resources. With respect to the sustainability of industrial production, it exists a legitimate demand for environmental protection which can be partially ensured by meaningful reuse of the waste resulting in the production of building materials with favourable materials properties and sufficiently high utility value comparable with building materials made of primary resources.

In the case of concrete, the main limiting factor from an environmental point of view is the production of cement which is currently the most widely used binder in the construction industry with rapidly increasing production in recent years $[1,2]$. The process of cement production is highly energy-demanding with accompanying high environmental impact. Global cement production is the third-largest source of anthropogenic emissions of $\mathrm{CO}_{2}$ after fossil fuels and land-use change [3] with approximate 5-8\% estimation of the total $\mathrm{CO}_{2}$ emissions [4-7]. Taking into consideration that global cement production has increased more than 30 times since 1950, estimated global emissions of $\mathrm{CO}_{2}$ were $1.5 \pm 0.12 \mathrm{Gt}$ in 2018, cumulative global emissions were of $38.3 \pm 2.4 \mathrm{Gt} \mathrm{CO}_{2}$ between 1928 and 2018, $71 \%$ of which have occurred since 1990 [3], it exists a legitimate demand on the use of alternative binders with significantly decreased influence on the environment or the use of recycled cementitious materials utilized in new concrete mixes.

Due to the importance of reutilization of recycled aggregates in newly produced cementitious materials, scientists already focused on such a topic. Silva et al. [8] presented a comprehensive review dealing with availability and processing of recycled aggregates within the construction and demolition supply chain with important conclusions concerning the quality control of the recycled materials. Krour et al. [9] focused on determination of the incorporation rate of various types of recycled aggregates in cement raw materials. Based on the data collected from three recycling plants located in Belgium and France they concluded that incorporation rate is mainly between $10-20 \%$, just occasionally below $5 \%$ or more than $30 \%$. Besides, various studies dealt with by their-own designed materials and determination of materials properties, e.g. Omrane and Rabehi [10] studied the effect of natural pozzolan and recycled concrete aggregates on thermal and physico-mechanical characteristics of self-compacting concrete and Berredjem et al. [11] focused on mechanical and durability properties of concrete based on recycled aggregates from demolished concrete.

In this paper, we focused on the design of three concrete mixtures with various dosages of coarse aggregates including the recycled ones originating from crushed concrete paving cobbles and their material characterization in terms of basic physical, thermal and hygric properties.

\section{Materials and Methods}

\subsection{Studied materials}

Three composites signed CREF, CREC1 and CREC2 were designed and studied in terms of basic physical, hygric and thermal properties. All the materials were based on cement binder CEM I 42.5 R Małogoszcz, w/c ratio equal to 0.45 and different dosages of 4 types of fillers (fine and coarse aggregates). Fine aggregates $(0-4 \mathrm{~mm})$ were represented by a natural river sand from the location Dwudniaki. Coarse aggregates involved two fractions of natural gravel from Dwudniaki of the particle size up to $16 \mathrm{~mm}$ and recycled concrete aggregates (crushed concrete paving cobbles) - Figure 1. In the case of CREF concrete, fine and coarse aggregates without the recycled one were used, CREC1 was made of all 4 types of aggregates with the mass ratio (recycled/total mass) equal to 0.5. CREC2 was made without the natural gravel with the mass ratio (recycled/total mass) equal to 0.65 . 
BASF BV 18 and BASF Glenium SKY 591 plasticizers were used in the amount of 0.9 and 1.4 wt. \%, respectively, to achieve favourable rheological properties of fresh mixtures. The composition of the designed mixtures is summarized in Table 1.

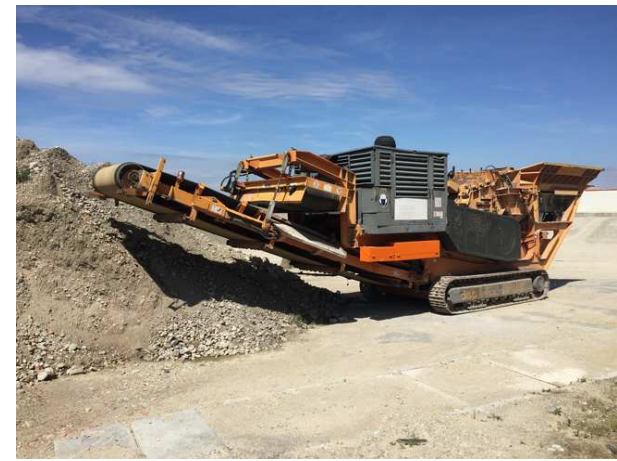

a)

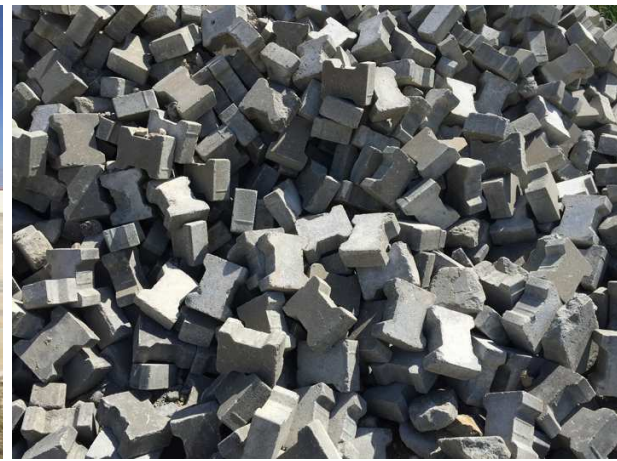

b)

Fig. 1. a) Machine used for preparation of recycled concrete aggregates $\mathbf{b}$ ) concrete paving cobbles.

Table 1. Composition of the studied materials.

\begin{tabular}{|c|c|c|c|}
\hline Component & CREF & CREC1 & CREC2 \\
\hline $\begin{array}{c}\text { CEM I } 42.5 \mathrm{R} \\
\text { Małogoszcz }\left[\mathrm{kg} / \mathrm{m}^{3}\right]\end{array}$ & 414 & 414 & 414 \\
\hline Water $\left[\mathrm{kg} / \mathrm{m}^{3}\right]$ & 186 & 186 & 186 \\
\hline $\mathrm{w} / \mathrm{c}[-]$ & 0.45 & 0.45 & 0.45 \\
\hline $\begin{array}{l}\text { Natural river sand } \\
0 / 4 \mathrm{~mm}\left[\mathrm{~kg} / \mathrm{m}^{3}\right]\end{array}$ & 615 & 281 & 569 \\
\hline Gravel $2 / 8 \mathrm{~mm}\left[\mathrm{~kg} / \mathrm{m}^{3}\right]$ & 580 & 281 & 0 \\
\hline Gravel $8 / 16 \mathrm{~mm}\left[\mathrm{~kg} / \mathrm{m}^{3}\right]$ & 562 & 264 & 0 \\
\hline $\begin{array}{c}\text { Recycled concrete } \\
\text { aggregates } 4 / 16 \mathrm{~mm} \\
{\left[\mathrm{~kg} / \mathrm{m}^{3}\right]}\end{array}$ & 0 & 825 & 1057 \\
\hline BASF 18BV [wt. \%] & 0.9 & 0.9 & 0.9 \\
\hline $\begin{array}{l}\text { BASF Glenium SKY } 91 \\
\text { [wt. \%] }\end{array}$ & 1.4 & 1.4 & 1.4 \\
\hline
\end{tabular}

In Figure 2, granulometries of four types of aggregates used within the production of samples are presented. In Figure 3, granulometries of the final mixes of aggregates used for preparation of CREF, CREC1 and CREC2 composites according to the Table 1 are given. 


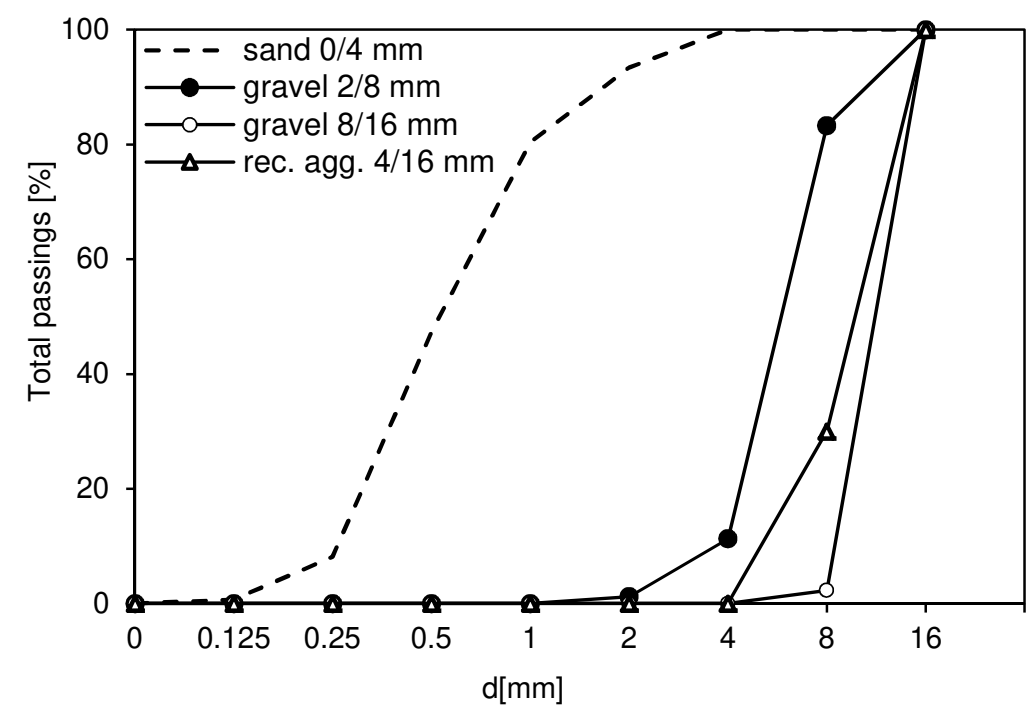

Fig. 2. Granulometry of the individual components of aggregates.

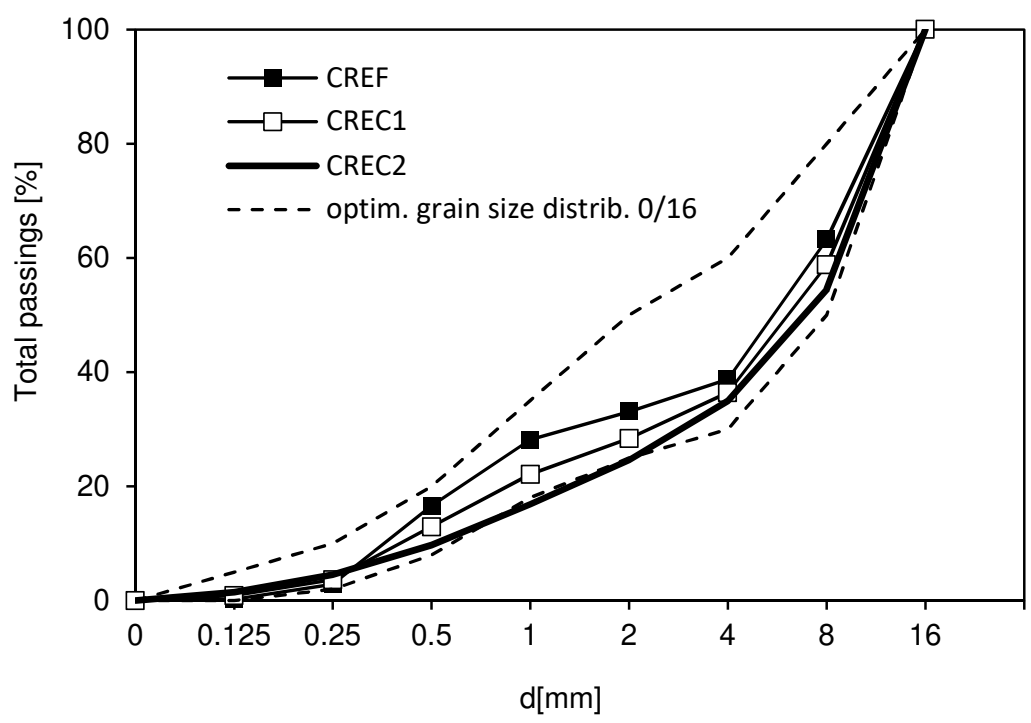

Fig. 3. Granulometry of mixes of aggregates used for preparation of the studied materials.

\subsection{Experimental methods}

The bulk density of the designed mixtures was determined by averaging of the values determined by the gravimetric method on the set of 4 cubic samples of the dimensions $50 \times 50 \times 50 \mathrm{~mm}^{3}$, 3 samples of the dimensions $100 \times 100 \times 100 \mathrm{~mm}^{3}$, and 3 prisms of the dimensions $40 \times 40 \times 150 \mathrm{~mm}^{3}$.

Thermal accumulation and transport properties (thermal conductivity, specific heat capacity, thermal diffusivity) were determined by a non-steady state method using ISOMET 2114 device that was equipped by a surface probe. Such measurements involve two measuring stages. In the first stage, the surface of the probe is heated up by a resistance 
wire embedded in the probe by a passing current which subsequently heats up the sample. In the second stage, turned off electrical power source results in cooling of the probe due to a dissipation of the thermal energy to the sample. Cooling down velocity determined by a thermocouple embedded in the probe is proportional to the thermal properties calculated by the device. Measurements were repeated 9- and 5-times on dry and fully water-saturated samples of the dimensions $100 \times 100 \times 100 \mathrm{~mm}^{3}$.

Water vapour diffusion resistance factor was experimentally determined by the dry- and the wet-cup methods on samples with dimensions $100 \times 100 \times 30 \mathrm{~mm}^{3}$. In the dry-cup method arrangement, silica gel was placed under the dry samples to ensure 0-3\% relative humidity (RH), cups with on-side insulated samples were placed into a climatic chamber with regulated $50 \% \mathrm{RH}$ and the mass increase was continuously monitored and evaluated after the linear dependence on time. Wet-cup experiments were performed by using water under the samples evaporating into a small space beneath the samples to ensure $97 \%$ RH against $50 \%$ in the climatic chamber and the mass decrease was monitored and evaluated in the same way as for the dry-cup experiment.

Water vapour sorption ability was determined on 4 samples per each set of the studied materials. The mass of the samples was in the range of $30-50 \mathrm{~g}$. Samples were placed into a desiccator with supersaturated solution of $\mathrm{K}_{2} \mathrm{SO}_{4}$ ensuring $97 \% \mathrm{RH}$ and the water vapour sorption capacity corresponding with the amount of water bonded in the porous body (one point of the sorption isotherm) was determined after reaching the mass equilibrium.

Hygric properties were determined on samples of the dimensions $50 \times 50 \times 50 \mathrm{~mm}^{3}$ by means of the vertical water sorption test. Samples were insulated on lateral sides by epoxy resin to ensure 1D water transport and the bottom side of the sample was continuously wetted by water from a water reservoir. Based on the observed time dependent increases in the mass of the samples, water absorption coefficients and the apparent moisture diffusivities were calculated.

\section{Results and discussion}

Basic physical properties were represented by the bulk density (Table 2) which was in the case of the reference composite (CREF) equal to $2236 \mathrm{~kg} / \mathrm{m}^{3}$. It was observed just a slight decrease $\sim 2 \%$ in the bulk density for the composites with additional fraction of recycled aggregates (CREC1, CREC2). Mechanical properties after 28 and 90 days are summarized in Table 2. Highest strengths were observed for CREC1 (56.8 and 65.2 MPa). Both composites with recycled aggregates were of better strength performance than CREF.

Table 2. Basic physical and mechanical properties.

\begin{tabular}{|c|c|c|c|}
\hline Quantity & CREF & CREC1 & CREC2 \\
\hline Bulk density $\left[\mathrm{kg} / \mathrm{m}^{3}\right]$ & 2236 & 2192 & 2192 \\
\hline$f_{c}-28$ days $[\mathrm{MPa}]$ & 46.1 & 56.8 & 54.5 \\
\hline$f_{c}-90$ days $[\mathrm{MPa}]$ & 52.2 & 65.2 & 64.0 \\
\hline
\end{tabular}

Thermal properties of the studied samples in dry- and wet-state are summarized in Table 3. Correspondingly with the bulk density, the thermal conductivity of the reference CREF concrete was highest $(2.41 \mathrm{~W} / \mathrm{m} \cdot \mathrm{K})$ and decreased to $1.84 \mathrm{~W} / \mathrm{m} \cdot \mathrm{K}(\mathrm{CREC} 1)$ and 2.08 $\mathrm{W} / \mathrm{m} \cdot \mathrm{K}(\mathrm{CREC} 2)$. Such decrease is mainly influenced by higher porosity of CREC1 and 
CREC2. The specific heat capacity was in the range $785-817 \mathrm{~J} / \mathrm{kg} \cdot \mathrm{K}$ without any significant difference between the studied materials. The thermal conductivity of wet concretes was about $10-25 \%$ higher than that in the dry state. Such an increase is in accordance with thermal conductivity values of air/water and the fact that air present in the pores was substituted by water.

Table 3. Thermal properties.

\begin{tabular}{|c|c|c|c|}
\hline Quantity & CREF & CREC1 & CREC2 \\
\hline $\begin{array}{l}\text { Thermal conductivity } \\
\text { (dry) }[\mathrm{W} / \mathrm{m} \cdot \mathrm{K}]\end{array}$ & 2.41 & 1.84 & 2.08 \\
\hline $\begin{array}{l}\text { Specific heat capacity } \\
\text { (dry) }[\mathrm{J} / \mathrm{kg} \cdot \mathrm{K}]\end{array}$ & 817 & 785 & 812 \\
\hline $\begin{array}{l}\text { Thermal diffusivity } \\
\text { (dry) }\left[\mathrm{m}^{2} / \mathrm{s}\right]\end{array}$ & $1.32 \cdot 10^{-6}$ & $1.07 \cdot 10^{-6}$ & $1.17 \cdot 10^{-6}$ \\
\hline $\begin{array}{c}\text { Thermal conductivity } \\
\text { (water-saturated) } \\
{[\mathrm{W} / \mathrm{m} \cdot \mathrm{K}]}\end{array}$ & 2.79 & 2.30 & 2.29 \\
\hline
\end{tabular}

Hygric properties are summarized in Table 4. In the case of the water vapour diffusion resistance factor, the lowest values were observed for CREF $\left(\mu_{d r y}=89.3, \mu_{\text {wet }}=42.9\right)$, whereas the highest for CREC2 $\left(\mu_{d r y}=131.0, \mu_{\text {wet }}=66.6\right)$. Water vapour sorption at $97 \%$ $\mathrm{RH}$ did not differ significantly and was in the range of $9.09-10.99 \mathrm{~m}^{3} / \mathrm{m}^{3}$. Water transport properties represented by the water absorption coefficient and the moisture diffusivity did not change fundamentally by utilization of recycled aggregates in comparison to the reference material, i.e. they were in the range of $\sim 4.54 \cdot 10^{-3}-1.30 \cdot 10^{-2} \mathrm{~kg} / \mathrm{m}^{2} \cdot \mathrm{s}^{1 / 2}$ and $1.46 \cdot 10^{-9}-1.58 \cdot 10^{-8} \mathrm{~m}^{2} / \mathrm{s}$, respectively.

Table 4. Hygric properties (water vapour, water).

\begin{tabular}{|c|c|c|c|}
\hline Quantity & CREF & CREC1 & CREC2 \\
\hline $\begin{array}{c}\text { Water vapour diffusion } \\
\text { resistance factor } \\
\text { (dry cup) [-] }\end{array}$ & 89.3 & 124.3 & 131.0 \\
\hline $\begin{array}{c}\text { Water vapour diffusion } \\
\text { resistance factor } \\
\text { (wet cup) [-] }\end{array}$ & 42.9 & 58.6 & 66.6 \\
\hline $\begin{array}{c}\text { Sorption isotherm } \\
97 \% \mathrm{RH}\left[\mathrm{m}^{3} / \mathrm{m}^{3}\right]\end{array}$ & 9.09 & 10.99 & 10.49 \\
\hline $\begin{array}{c}\text { Water absorption } \\
\text { coefficient }\left[\mathrm{kg} / \mathrm{m}^{2} \cdot \mathrm{s}^{1 / 2}\right]\end{array}$ & $8.02 \cdot 10^{-3}$ & $1.30 \cdot 10^{-2}$ & $4.54 \cdot 10^{-3}$ \\
\hline $\begin{array}{c}\text { Moisture diffusivity } \\
{\left[\mathrm{m}^{2} / \mathrm{s}\right]}\end{array}$ & $7.13 \cdot 10^{-9}$ & $1.58 \cdot 10^{-8}$ & $1.46 \cdot 10^{-9}$ \\
\hline
\end{tabular}

\section{Conclusions}

In this paper, materials characterization of three designed concretes based on four types of aggregates including the recycled one was introduced. The reference material consisted of natural fine and coarse aggregates, whereas the two designed materials involved a particular 
amount of recycled paving cobbles which were crushed to the fraction 4/16 mm. Observed materials properties involved basic physical, mechanical, thermal and hygric properties.

Results revealed that the compressive strengths of concretes with recycled aggregates (CREC1, CREC2) after 28 and 90 days were higher than those of the reference concrete CREF which is positive a positive fact with respect to meaningful utilization of waste materials. Significant changes were observed in the case of the water vapour diffusion and the thermal conductivity (slight shift to more insulative behaviour). Such properties are significantly dependent on the porosity and structure of the porous body which should be further studied by using mercury intrusion and gas porosimetry methods.

This research has been supported by the Grant Agency of the Czech Technical University in Prague under project No. SGS19/143/OHK1/3T/11, Ministry of Science and Technology (MOST, Taiwan) under the project MOST-108-2221-E-197-006, and by EMMAT project E-mobility and sustainable materials and technologies PPI/APM/2018/00027 financed by the Polish National Agency for Academic Exchange (NAWA).

\section{References}

1. M. B. Ali, R. Saidur, M.S. Hossain, Renew. \& Sust. Energ. Rev. 15, 2252-2261 (2011)

2. J. X. Wei, K. Cen, Y.B. Geng, Mitig. Adapt. Strat. Gl. 24 (2), 301-328 (2019)

3. R. M. Andrew, Earth Syst. Sci. Data 11 (4), 1675-1710 (2019)

4. F. Ascione, Sol. Energy 154, 34-100 (2017)

5. M. D. Gavriletea, Sustainability 9 (7), 1118 (2017)

6. S. Monkman, M. MacDonald, Constr. Build. Mater. 124, 127-132 (2016)

7. O. Omosebi, H. Maheshwari, R. Ahmed, S. Shah, S. Osisanya, S. Hassani, G. DeBruijn, W. Cornell, D. Simon, Cem. Concr. Compos. 74, 54-70 (2016)

8. R. V. Silva, J. de Brito, R.K. Dhir, J. Clean. Prod. 143, 598-614 (2017)

9. H. Krour, R. Trauchessec, A. Lecomte, C. Diliberto, L. Barnes-Davin, B. Bolze, A. Delhay, Constr. Build. Mater. 248, 118217 (2020)

10. M. Omrane, M. Rabehi, Constr. Build. Mater. 247, 118576 (2020)

11. L. Berredjem, N. Arabi, L. Molez, Constr. Build. Mater. 246, 118421 (2020) 